\title{
Impact of inflammatory bowel disease on daily life: an online survey by the Korean Association for the Study of Intestinal Diseases
}

\author{
Young Sun Kim ${ }^{1}$, Sung-Ae Jung ${ }^{2}$, Kang-Moon Lee ${ }^{3}$, Soo Jung Park ${ }^{4}$, Tae Oh Kim ${ }^{5}$, Chang Hwan Choi ${ }^{6}$, \\ Hyun Gun Kim ${ }^{7}$, Won Moon ${ }^{8}$, Chang Mo Moon ${ }^{2}$, Hye Kyoung Song ${ }^{2}$, Soo-Young Na ${ }^{9}$, Suk-Kyun Yang ${ }^{10}$, \\ Korean Association for the Study of Intestinal Diseases (KASID) \\ ${ }^{1}$ Department of Internal Medicine, Seoul National University Healthcare System Gangnam Center, Seoul, ${ }^{2}$ Department of Internal Medicine, \\ Ewha Womans University School of Medicine, Seoul, ${ }^{3}$ Department of Internal Medicine, St. Vincent's Hospital, The Catholic University of Korea \\ College of Medicine, Suwon, ${ }^{4}$ Department of Internal Medicine, Yonsei University College of Medicine, Seoul, ${ }^{5}$ Department of Internal Medicine, \\ Haeundae Paik Hospital, Inje University College of Medicine, Busan, ${ }^{6}$ Department of Internal Medicine, Chung-Ang University College of \\ Medicine, Seoul, ${ }^{7}$ Department of Internal Medicine, Soonchunhyang University College of Medicine, Seoul, ${ }^{8}$ Department of Internal Medicine, \\ Kosin University College of Medicine, Busan, ${ }^{9}$ Department of Internal Medicine, Jeju National University School of Medicine, Jeju, ${ }^{10}$ Department \\ of Internal Medicine, University of Ulsan College of Medicine, Seoul, Korea
}

Background/Aims: Inflammatory bowel disease (IBD) is a chronic disabling gastrointestinal disorder that diminishes the quality of life of the affected individuals. Limited data are available regarding the impact of IBD on the daily life of Koreans. Methods: Self-administered, computer-aided, internet-based questionnaires were distributed to members of a Korean patient organization for IBD from March to April 2013, by the Korean Association for the Study of Intestinal Diseases. Results: A total of 599 patients with IBD (387 with Crohn's disease [CD] and 212 with ulcerative colitis [UC]) were enrolled. The majority of patients (81\%) expressed feelings of fatigue, weakness, and being worn out in their daily lives during times of flare; this percentage was reduced to $61 \%$ during remission. Respondents were absent from work or school for an average period of 18 days because of illness, within the first 6 months; the majority of respondents (64\%) felt stressed about their absence. Forty-six percent of the respondents reported having received unfair comments at work, or having suffered discrimination. Forty-seven percent of the respondents felt that IBD had negatively affected their income and earnings. Compared with patients with UC, those with CD reported a more frequent negative impact of IBD on work, or more economic burden. More than half of the respondents (61\%) reported that IBD had prevented them from making or keeping friends. Conclusions: IBD significantly impacts daily life, including work, education, and social relationships. Treatment that addresses the full spectrum of life of a patient would be more effective. (Intest Res 2017;15:338-344)

Key Words: Inflammatory bowel disease; Crohn disease; Colitis, ulcerative; Quality of life; Surveys and questionnaires

Received April 11, 2016. Revised August 7, 2016. Accepted August 8, 2016. Published online May 29, 2017

Correspondence to Sung-Ae Jung, Department of Internal Medicine, Ewha Womans University School of Medicine, 1071 Anyangcheon-ro, Yangcheongu, Seoul 07985, Korea. Tel: +82-2-2650-5053, Fax: +82-2-2655-2076, E-mail: jassa@ewha.ac.kr

Financial support: None. Conflict of interest: None.

\section{INTRODUCTION}

Although the incidence rate of IBD in Asian countries is considerably lower than the rate in Western countries, the burden of IBD has been rapidly increasing in Korea. ${ }^{1-3}$ However, public awareness about IBD is still low in Korea. Delay in the diagnosis of IBD could delay therapy, which can worsen the outcome. ${ }^{4-7}$

\footnotetext{
( ) Copyright 2017. Korean Association for the Study of Intestinal Diseases. All rights reserved.

This is an Open Access article distributed under the terms of the Creative Commons Attribution Non-Commercial License (http://creativecommons.org/licenses/by-nc/4.0)

which permits unrestricted non-commercial use, distribution, and reproduction in any medium, provided the original work is properly cited.
} 
IBD mainly consists of UC and CD. These are chronic disabling gastrointestinal disorders that diminish the quality of life (QOL) of the patient. ${ }^{5,8-10}$ Patients with IBD more frequently receive disability allowances than those received by age-matched individuals from the general population, ${ }^{5,6,10}$ which proves the detrimental effects of IBD on healthrelated QOL and productivity. ${ }^{5,8}$ A recent large-scale study (comprising 4,670 patients with IBD from 25 countries) conducted by the European Federation of Crohn's and Ulcerative Colitis Associations (EFCCA) reported the detrimental effects of IBD on intimate relationships, and the unfair comments received by the patients with regard to their work performance. ${ }^{8}$

However, limited studies have assessed the impact of IBD on the life of patients in Korea, with the majority of studies having been conducted in Western cohorts. ${ }^{5,68-10}$ In addition, there is little public knowledge regarding IBD and the chronic suffering of patients in Korea.

To overcome these issues, the Korean Association for the Study of Intestinal Diseases (KASID) has been conducting the "Happy Bowel Campaign" since 2013 to raise public awareness of IBD in general and to provide accurate information regarding the importance of early diagnosis and proper treatment to patients with IBD. In addition, the KASID is a promoter of World IBD Day, held every year on May 19.

This study reports the findings of a KASID-sponsored survey that aimed to investigate the impact of IBD on the daily lives of patients in Korea.

\section{METHODS}

\section{Study Population}

Patients with UC or CD were enrolled. Self-administered, computer-aided, internet-based questionnaires were distributed to them by the KASID, from March to April 2013. The KASID advertised the study through the Korean IBD patient advocacy and support group newsletter and website, and through online advertisements during the Happy Bowel Campaign. The purpose of the study was explained to patients at the time of enrollment. The survey was anonymous and the data were analyzed without revealing the personal details of the patients. Patients who had no Internet access were excluded, since the survey was only available online. Responding to the survey questions was considered consent to participate.

\section{Survey}

The survey was designed by KASID members of the International Affairs Committee Secretary of Liaison \& Public Relations in cooperation with a communications company "Communication Works." The survey was based primarily on the IMPACT survey of the EFCCA and on previously published reports ${ }^{8}$ on the QOL of patients with IBD. The survey consisted of 68 questions divided into 6 categories: (1) demographics, (2) experience with IBD, (3) overall impact on life, (4) overall impact on work, (5) overall economic impact, and (6) impact on relationships (Supplementary Material 1).

Some questions regarding "flare" and "remission" were short-answer questions. Most questions were closed ended, and participants were allowed to select one applicable option. The extent of "flare" and "remission" was open to patient interpretation. The questions concerning the overall impact of IBD were measured using a 5-point Likert scale (strongly agree, 5; agree, 4; neither agree nor disagree, 3; disagree, 2; strongly disagree, 1). In these cases, disagree or strongly disagree represented "no" and the other responses represented "yes."

\section{Statistical Analysis}

The collected data were analyzed using SPSS for Windows version 22.0 statistical software (IBM Corp., Armonk, NY, USA). With regard to statistical accuracy, a range of $\pm 2.53 \%$ (95\% CI limits) was set. Descriptive statistics and multiple linear regression analysis were used to analyze the responses, with subanalyses of patients with CD and UC. Subgroup differences were calculated using the chi-square test.

\section{Ethics}

The study was approved by the Seoul National University Ethics Committee (number: E-1403-037-563), with the completion and return of the survey implying consent to participate.

\section{RESULTS}

\section{Demographics}

A total of 599 patients with IBD (387 [64.6\%] with CD and 212 [35.4\%] with UC) completed the survey. Demographic and baseline data for all respondents are shown in Fig. 1. The majority of respondents were male $(69.6 \%)$ in both the 
CD and UC subgroups. The majority of participants (59\%) reported a period of more than 5 years since the diagnosis of IBD ( $60 \%$ of the patients in the CD subgroup and $57 \%$ of the patients in the UC subgroup).

\section{Experience with IBD}

Most respondents (84\%) from the CD and UC groups reported IBD being chronically active, whereas $16 \%$ reported being in remission. Sixty-five percent of the patients had been admitted to a hospital for IBD within the 5 years preceding the study; however, the proportion of patients with

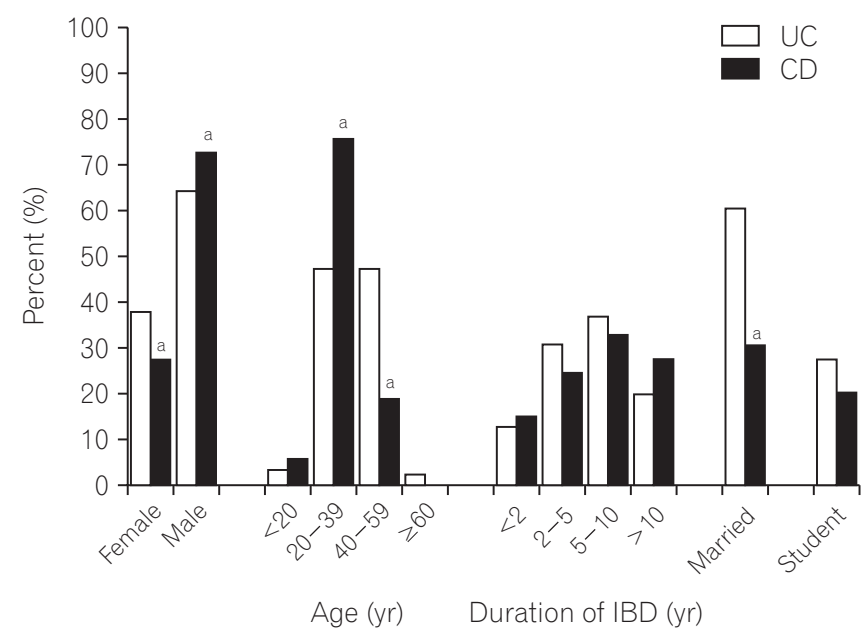

Fig. 1. Baseline characteristics of patients with IBD. ${ }^{a} P<0.05$, compared with patients with UC.
CD was significantly higher than the proportion of patients with UC $(76 \%, P<0.001)$, with regard to the hospitalization. Thirty-eight percent of the patients received emergency care before being diagnosed with IBD. Eighteen percent of the respondents had experienced a surgical procedure because of IBD. More patients with CD than with UC reported this experience $(P<0.001)$ (Table 1$)$.

Forty-one percent of the respondents reported visiting a hospital 6 months after they noticed the first symptoms related to IBD. The time before the first hospital visit was significantly longer in patients with $\mathrm{CD}(P<0.001)$. The reasons for delayed hospital visit were lack of knowledge about IBD (75\%), mild symptoms (13\%), inconvenient hospital access (3\%), economic burden (3\%), and others (6\%). Most respondents $(75 \%)$ received a final diagnosis within a year after they first noticed the symptoms. The other $25 \%$ patients received a final diagnosis after more than a year; in 3\% of these, IBD was diagnosed after 5 years from their first symptoms. The time required for final diagnosis was also significantly longer in patients with $\mathrm{CD}(P<0.001)$ (Table 1).

About three-quarters of the respondents reported undergoing current treatment by a gastroenterologist (75\%), while $13 \%$ reported undergoing current treatment by a primary physician. The most commonly taken drug among the respondents was 5 -aminosalicylates (69\%), followed by immunosuppressive agents (48\%), corticosteroids (15\%), and biological drugs (11\%). More patients with CD than with UC were being treated with biological drugs ( $15 \%$ and $5 \%$, respectively) at the time of conducting the study. Sixty-one

Table 1. Experience with IBD

\begin{tabular}{|c|c|c|c|}
\hline & $C D(n=387)$ & UC $(n=212)$ & $P$-value \\
\hline Chronically active condition & $325(84)$ & $178(84)$ & 1.000 \\
\hline In remission & $62(16)$ & $34(16)$ & 1.000 \\
\hline Hospitalization in the past $5 \mathrm{yr}$ & $294(76)$ & $98(46)$ & $<0.001$ \\
\hline Emergency care before diagnosis of IBD & $186(48)$ & $40(19)$ & $<0.001$ \\
\hline \multicolumn{4}{|c|}{ Time to hospital visit since noticing first symptoms (mo) } \\
\hline$<6$ & $208(54)$ & $145(68)$ & $<0.001$ \\
\hline$\geq 6$ & $179(46)$ & $67(32)$ & $<0.001$ \\
\hline \multicolumn{4}{|c|}{ Time required to receive the final diagnosis since noticing the first symptoms (mo) } \\
\hline
\end{tabular}

Values are presented as number (\%). 
percent of the patients had experienced side effects from corticosteroids, and $87 \%$ of the patients were concerned about the long-term effects of corticosteroids.

\section{Overall Impact of IBD on Life}

The majority of patients (81\%) expressed feelings of fatigue, weakness, and being worn out in their daily lives during times of flare; this percentage was reduced to $61 \%$ during remission. Most patients (68\%) felt stressed and were psychologically affected even during remission. Thirty-seven percent of the patients reported that they felt like committing suicide (CD $41 \%$ vs. UC $30 \%, P=0.01$ ). Multiple linear regression analysis revealed that previous emergency care $(P=0.021)$, previous hospitalizations $(P=0.036)$, previous surgeries $(P=0.035)$, experience of abdominal pain $(\mathrm{P}=0.008)$, and using biologics $(P=0.020)$ were associated with the feeling of committing suicide. Most patients $(74 \%)$ were anxious about their future (Table 2). Young age $(P=0.047)$, low income $(P=0.026)$, and experience of abdominal pain $(P<0.001)$ were associated with anxiety about the future, as per multivariable regression analysis.

\section{Overall Impact of IBD on Work}

More than half (52\%) of the respondents reported absence from work or school because of illness within the past 6 months (mean, 18 days). Younger patients and patients with CD had had more sick days; the mean period absence owing to sickness was 10 days for those $>40$ years of age and 23 days for those $<40$ years of age $(P<0.001)$, and 20 days versus 14 days for patients with $\mathrm{CD}$ and $\mathrm{UC}$, respectively $(P<0.001)$. The absence from work/school owing to IBD caused stress in $64 \%$ of the respondents. Compared to patients with UC, those with $\mathrm{CD}$ reported a more frequent negative impact of IBD on work (Table 3$)$. The use of biologics $(P=0.007)$ and steroids $(P=0.001)$, previous hospitalization $(P=0.043)$, previous surgeries $(P=0.009)$, and abdominal pain $(P=0.001)$ were associated with the negative impact of IBD on work, as per multiple linear regression analysis.

\section{Overall Economic Impact of IBD}

Forty-one percent of the respondents reported decreased QOL owing to the economic burden caused by IBD. Twentyone percent of the respondents had stopped medical treat-

Table 2. Overall Impact of IBD on Daily Life

\begin{tabular}{|c|c|c|c|}
\hline & $C D(n=387)$ & UC $(n=212)$ & $P$-value \\
\hline Felt tired, weak, and worn out in daily life during flare-ups & $311(80)$ & $174(81)$ & 0.664 \\
\hline Felt tired, weak, and worn out in daily life during remission & $238(61)$ & $127(60)$ & 0.727 \\
\hline Having felt like committing suicide & $158(41)$ & $64(30)$ & 0.010 \\
\hline Having felt anxiety about the future & 302 (78) & $141(67)$ & 0.003 \\
\hline
\end{tabular}

Values are presented as number (\%).

Table 3. Overall Impact of IBD on Work

\begin{tabular}{|c|c|c|c|}
\hline & $C D(n=387)$ & UC $(n=212)$ & $P$-value \\
\hline Left office or school early & $220(57)$ & $80(38)$ & $<0.001$ \\
\hline Absence from work or school & $228(59)$ & $83(39)$ & $<0.001$ \\
\hline Felt stress about taking time off work or school & $271(70)$ & $112(53)$ & $<0.001$ \\
\hline Received unfair comments at work or school & $155(40)$ & $52(25)$ & $<0.001$ \\
\hline Decline in income or academic ability & $200(52)$ & $80(38)$ & 0.010 \\
\hline Unable to perform to their full potential & $252(66)$ & $119(56)$ & 0.035 \\
\hline
\end{tabular}

values are presented as number (\%). 
Table 4. Overall Economic Impact of IBD

\begin{tabular}{|c|c|c|c|}
\hline & $C D(n=387)$ & $U C(n=212)$ & $P$-value \\
\hline Stopped medical treatment owing to economic burden & $96(25)$ & $30(14)$ & 0.002 \\
\hline IBD had negatively affected the income & $201(52)$ & $180(38)$ & $<0.001$ \\
\hline Decreased quality of life owing to the economic burden & $170(44)$ & $77(36)$ & 0.082 \\
\hline
\end{tabular}

Values are presented as number (\%).

Table 5. Impact of IBD on Relationships

\begin{tabular}{|c|c|c|c|}
\hline & $C D(n=387)$ & $U C(n=212)$ & $P$-value \\
\hline Prevented from making or keeping friends & $237(62)$ & $126(59)$ & 0.663 \\
\hline Had to end an intimate relationship end owing to IBD & $182(47)$ & $100(47)$ & 1.000 \\
\hline Meeting others with IBD made them more optimistic & $120(31)$ & $67(32)$ & 0.927 \\
\hline Patient association had a beneficial impact on their life & $258(67)$ & $161(76)$ & 0.020 \\
\hline
\end{tabular}

Values are presented as number (\%).

ment because of the economic burden. Those with CD reported an economic burden more often than those with UC (Table 4$)$. Male gender $(P=0.001)$, old age $(P=0.011)$, low income $(P=0.008)$, use of steroids $(P=0.039)$ and biologics ( $P=0.023)$, previous hospitalization $(P=0.048)$, and previous surgeries $(P=0.002)$ were associated with high economic burden, as per multivariable regression analysis.

\section{Impact of IBD on Relationships}

Sixty-one percent of the patients reported that IBD had prevented them from making or keeping friends. Nearly half of the respondents (47\%) reported having had to end an intimate relationship owing to IBD. Most of the respondents $(70 \%)$ reported that the patient association had a beneficial impact on their life (Table 5$)$. Young age $(P=0.002)$, previous surgeries $(P=0.003)$, and previous hospitalization $(P=0.038)$ were associated with the negative impact of IBD on relationships, as per multivariable regression analysis.

\section{DISCUSSION}

IBD is typically diagnosed in childhood or early adulthood, and is a lifelong condition. ${ }^{5,8-10}$ Although IBD does not reduce life expectancy, it has a substantial impact on health-related QOL., ${ }^{8,11,12}$ The present study reports the experience of IBD among Korean patients and the impact of IBD on their daily life. Most patients with IBD were tired, weak and worn out in their daily life during a remission as well as during flareups. A large number of patients reported that IBD adversely affected their QOL. This negative impact of IBD was more severe in patients with CD than in those with UC. A previous experience of surgeries, and hospitalization due to IBD were associated with this negative impact. In general, chronic fatigue has been found to be more prevalent in patients with IBD than in healthy subjects, ${ }^{9,13,14}$ which, in turn, diminishes the health-related QOL in IBD. ${ }^{9}$ Accordingly, physicians should remember that fatigue is an important symptom of IBD that impacts the health-related QOL of the patients.

In this study, the time from onset of symptoms of IBD to hospital visit was long; over $41 \%$ of the patients had been symptomatic for at least 6 months before visiting a clinician. The most common cause of delayed hospital visit was lack of patient's knowledge about the disease. In addition, although most responders reported establishment of a final diagnosis within 12 months after noticing the first symptoms, $25 \%$ of the patients waited for more than a year for the final diagnosis. The delay in meeting a specialist and emergency department visit was more striking for patients with CD than for those with UC. Population-based cohort studies reported that one-fifth to one-third of the patients with CD have complications such as stricture, abscess and/or fistula at the time of diagnosis. ${ }^{15,16}$ Functional gastrointestinal disorders such as IBS often mimic early manifestations of IBD, and infectious diseases such as intestinal tuberculosis, which mimic IBD, can hinder accurate assessment of the disease 
in Korea, thereby delaying hospital visit or referral to IBD specialists. ${ }^{7,17,18}$ In the IMPACT survey, only $54 \%$ of the 4,670 patients received a final diagnosis within 1 year after noticing the first symptoms. About $20 \%$ of the patients received a final diagnosis after more than 5 years. The majority of patients (67\%) had visited an emergency department at least once before their diagnosis. ${ }^{8}$ Timely diagnosis and treatment would help reduce the health care burden of hospitals, including prediagnosis hospital visits or admissions. ${ }^{8,19} \mathrm{~Pa}-$ tients with IBD tend to require emergency room or primary clinic care prior to diagnosis; thus, awareness about IBD is necessary among emergency care staff or primary physicians. $^{8}$

About 15\% of the respondents received corticosteroid therapy, which was a concern for most of them. Corticosteroid use should be consistent with the guidelines, and the advantages and possible detrimental effects should be discussed with patients. ${ }^{8,20-22}$

The fluctuations and unpredictable exacerbations of IBD symptoms have a significant psychological impact on the patient's life. Fears related to the long-term effects of treatments, and the progression of the disease can exacerbate anxiety and depression. ${ }^{11,23-25}$ In the present study, 37\% of the patients reported having felt like committing suicide. Most patients were anxious about their future. The prevalence of anxiety and/or depression in patients with IBD has been reported to be $35 \%$ during remission; ${ }^{24}$ the prevalence of anxiety and depression during relapse has been reported to be $80 \%$ and $60 \%$, respectively. ${ }^{25}$ In a recent study, Korean patients with IBD showed higher levels of depression and impaired health-related QOL than those shown by healthy controls. ${ }^{26}$ The negative perceptions of IBD among patients and the depressive mood can increase treatment nonadherence, leading to a poorer outcome. ${ }^{19}$ Integrating psychological interventions with conventional medical treatment seems prudent. ${ }^{11}$

IBD had a considerable impact on work and economic burden in the present study. Many patients, especially young respondents and those with $\mathrm{CD}$, had missed school or work in the 6 months prior to the study, consistent with other reports, ${ }^{8,27}$ which, for many patients, is a source of stress and can be the basis for hurtful comments or employment problems. Accordingly, medical discussions should consider work and economic burden as important facets of treatment among Korean patients with IBD.

With regard to building human relationships, IBD can lead to decreased physical intimacy and social activity. ${ }^{28,29} \mathrm{Be}-$ ing able to talk about IBD-related problems in a supportive group setting was helpful for many respondents, as was the awareness created by health care professionals regarding the influence of IBD on these aspects of life.

This study had several limitations. Firstly, the survey was a self-completed instrument and was only available online, so individuals without Internet access could not participate. Thus, the results cannot be generalized to the entire population. Secondly, the survey questionnaire was not validated. Finally, self-assessment introduces the possibility of recall bias concerning aspects such as medication use and emergency care. Some patients might have overestimated the negative impact of IBD on their lives.

Despite the limitations, our study is meaningful because it is the first large-scale study to investigate the effects on IBD on the daily life of Korean patients. The results would be valuable in devising strategies of care, and campaigns to increase the awareness of IBD in Korea.

In conclusion, IBD considerably affects the daily life of the patients, including their work, school, and social relationships. Treatment that addresses that full spectrum of a patient's life would be more effective.

\section{REFERENCES}

1. Yang SK, Yun S, Kim JH, et al. Epidemiology of inflammatory bowel disease in the Songpa-Kangdong district, Seoul, Korea, 1986-2005: a KASID study. Inflamm Bowel Dis 2008;14:542549.

2. Lee JW, Im JP, Cheon JH, Kim YS, Kim JS, Han DS. Inflammatory bowel disease cohort studies in Korea: present and future. Intest Res 2015;13:213-218.

3. Choi JH, Kim ES, Cho KB, et al. Old age at diagnosis is associated with favorable outcomes in Korean patients with inflammatory bowel disease. Intest Res 2015;13:60-67.

4. Sewell JL, Velayos FS. Systematic review: the role of race and socioeconomic factors on IBD healthcare delivery and effectiveness. Inflamm Bowel Dis 2013;19:627-643.

5. Peyrin-Biroulet L, Cieza A, Sandborn WJ, et al. Development of the first disability index for inflammatory bowel disease based on the international classification of functioning, disability and health. Gut 2012;61:241-247.

6. Peyrin-Biroulet L, Billioud V, D'Haens G, et al. Development of the Paris definition of early Crohn's disease for disease-modification trials: results of an international expert opinion process. Am J Gastroenterol 2012;107:1770-1776.

7. Hu PJ. Inflammatory bowel disease in Asia: the challenges and opportunities. Intest Res 2015;13:188-190. 
8. Lönnfors S, Vermeire S, Greco M, Hommes D, Bell C, Avedano L. IBD and health-related quality of life: discovering the true impact. J Crohns Colitis 2014;8:1281-1286.

9. Romberg-Camps MJ, Bol Y, Dagnelie PC, et al. Fatigue and health-related quality of life in inflammatory bowel disease: results from a population-based study in the Netherlands: the IBD-South Limburg cohort. Inflamm Bowel Dis 2010;16:21372147.

10. Haapamäki J, Roine RP, Sintonen H, Turunen U, Färkkilä MA, Arkkila PE. Health-related quality of life in inflammatory bowel disease measured with the generic 15D instrument. Qual Life Res 2010;19:919-928.

11. Sajadinejad MS, Asgari K, Molavi H, Kalantari M, Adibi P. Psychological issues in inflammatory bowel disease: an overview. Gastroenterol Res Pract 2012;2012:106502.

12. Hall NJ, Rubin GP, Dougall A, Hungin AP, Neely J. The fight for 'health-related normality': a qualitative study of the experiences of individuals living with established inflammatory bowel disease (IBD). J Health Psychol 2005;10:443-455.

13. Jelsness-Jørgensen LP, Bernklev T, Henriksen M, Torp R, Moum BA. Chronic fatigue is associated with impaired health-related quality of life in inflammatory bowel disease. Aliment Pharmacol Ther 2011;33:106-114.

14. Yoo S, Jung YS, Park JH, et al. Fatigue severity and factors associated with high fatigue levels in Korean patients with inflammatory bowel disease. Gut Liver 2014;8:148-153.

15. Thia KT, Sandborn WJ, Harmsen WS, Zinsmeister AR, Loftus EV Jr. Risk factors associated with progression to intestinal complications of Crohn's disease in a population-based cohort. Gastroenterology 2010;139:1147-1155.

16. Kim YS. What is the important issue to prevent the postoperative Crohn's disease? Intest Res 2014;12:85-86.

17. Danese S, Fiorino G, Mary JY, et al. Development of red flags index for early referral of adults with symptoms and signs suggestive of Crohn's disease: an IOIBD initiative. J Crohns Colitis 2015;9:601-606

18. Kim ES, Kim WH. Inflammatory bowel disease in Korea: epidemiological, genomic, clinical, and therapeutic characteristics. Gut Liver 2010;4:1-14.
19. Devlen J, Beusterien K, Yen L, Ahmed A, Cheifetz AS, Moss AC. The burden of inflammatory bowel disease: a patient-reported qualitative analysis and development of a conceptual model. Inflamm Bowel Dis 2014;20:545-552.

20. Dignass A, Van Assche G, Lindsay JO, et al. The second European evidence-based consensus on the diagnosis and management of Crohn's disease: current management. J Crohns Colitis 2010;4:28-62.

21. Ye BD, Yang SK, Shin SJ, et al. Guidelines for the management of Crohn's disease. Intest Res 2012;10:26-66.

22. Choi CH, Kim YH, Kim YS, et al. Guidelines for the management of ulcerative colitis. Intest Res 2012;10:1-25.

23. Walker JR, Ediger JP, Graff LA, et al. The Manitoba IBD cohort study: a population-based study of the prevalence of lifetime and 12-month anxiety and mood disorders. Am J Gastroenterol 2008;103:1989-1997.

24. Mittermaier C, Dejaco C, Waldhoer T, et al. Impact of depressive mood on relapse in patients with inflammatory bowel disease: a prospective 18-month follow-up study. Psychosom Med 2004;66:79-84.

25. Addolorato G, Capristo E, Stefanini GF, Gasbarrini G. Inflammatory bowel disease: a study of the association between anxiety and depression, physical morbidity, and nutritional status. Scand J Gastroenterol 1997;32:1013-1021.

26. Kim ES, Cho KB, Park KS, et al. Predictive factors of impaired quality of life in Korean patients with inactive inflammatory bowel disease: association with functional gastrointestinal disorders and mood disorders. J Clin Gastroenterol 2013;47:e38e44.

27. Bernklev T, Jahnsen J, Henriksen M, et al. Relationship between sick leave, unemployment, disability, and health-related quality of life in patients with inflammatory bowel disease. Inflamm Bowel Dis 2006;12:402-412.

28. Daniel JM. Young adults' perceptions of living with chronic inflammatory bowel disease. Gastroenterol Nurs 2002;25:83-94.

29. Kemp K, Griffiths J, Lovell K. Understanding the health and social care needs of people living with IBD: a meta-synthesis of the evidence. World J Gastroenterol 2012;18:6240-6249. 
See "Impact of inflammatory bowel disease on daily life: an online survey by the Korean Association for the Study of Intestinal Diseases" on page 338.

Supplementary Material 1. A Survey of Patients with Inflammatory Bowel Disease (IBD)

\section{Demographics}

\begin{tabular}{|c|c|}
\hline Sex & 1. Male 2. Female \\
\hline Age & $\begin{array}{l}\text { (1) Less than } 10 \text { years }[<10 \text { years] } \\
\text { (2) } 10 \sim 19 \text { years } \\
\text { (3) } 20 \sim 24 \text { years } \\
\text { (4) } 25 \sim 29 \text { years } \\
\text { (5) } 30 \sim 34 \text { years } \\
\text { (6) } 35 \sim 39 \text { years } \\
\text { (7) } 40 \sim 44 \text { years } \\
\text { (8) } 45 \sim 49 \text { years } \\
\text { (9) } 50 \sim 54 \text { years } \\
\text { (10) } 55 \sim 59 \text { years } \\
\text { (11) } 60 \sim 64 \text { years } \\
\text { (12) }>65 \text { years }\end{array}$ \\
\hline Marital status & (1) Single (2) Married \\
\hline Occupied area & $\begin{array}{l}\text { (1) Seoul } \\
\text { (2) Metropolitan City (Busan, Gwangju, Daegu, Daejeon, Incheon, Ulsan) } \\
\text { (3) City } \\
\text { (4) Town } \\
\text { (5) Other ( ) }\end{array}$ \\
\hline Society membership status & $\begin{array}{l}\text { (1) The Crohn's Family Lovers Committee } \\
\text { (2) UC Lovers Committee } \\
\text { (3) Other ( ) } \\
\text { (4) Not joined }\end{array}$ \\
\hline
\end{tabular}


- Which disease of IBD are you diagnosed?

(1) Corhn's disease (CD) (2) Ulcerative colitis (UC) (3) Other ( )

- Which is a period of the applicable disease?

(1) 2 years (2) 2- 5 years (3) 5-10 years (4) $>10$ years

- Which is the current treatment drug/therapeutic measures?

(1) Steroids (2) 5 ASA (asacol() pentasa() salofalk() zopyrin( ))

(3) Salazine (4) Colazal (5) Immunomodulator (6) Biologics (7) Probiotics

\section{Experience with IBD - Disease Diagnosis and Current Status}

1. When did you experience the symptoms of IBD first?
(1) 1 year or less
(2) 1-3 years ago
(3) 4-5 years ago
(4) 6 7 years ago
(5) $7 \sim 9$ years ago
(6) over 10 years ago

2. When did you visit a hospital due to IBD after you experienced first symptom?
(1) within 1 month
(2) $1 \sim 3$ months
(3) $3 \sim 6$ months
(4) 6 month 1 year
(5) 1 year 2year
(6) $2 \sim 5$ years
(7) over 5 years

2-1. Why you visited a hospital after a year passed since you have experienced symptom?

(1) Because symptoms were not severe

(2) Did not notice disease

(3) Have no time

(4) Could not afford it financially

(5) Have difficulty in visiting a hospital and getting a diagnosis

(6) Did not know which hospital I should visit

(7) Other ( )

3. How long did it take to get final IBD diagnosis through a health care professional since you noticed first symptoms?
(1) $<3$ months
(2) $3 \sim 6$ months
(3) 6 months 1 year
(4) $1 \sim 2$ years
(5) $2 \sim 5$ years
(6) $\geq 5$ years

4. Have you ever visited the emergency room because of emergency situations caused by IBD before you got diagnosed? If so, how many times did you visit?
(1) Yes (
times)
(2) No

5. Which is the current status of IBD?
(1) Asymptomatic status
(2) Have symptoms, but they are controlled by medicine
(3) Status that symptoms are changed for the better or worse

6. Have you ever hospitalized in the past 5 years? If so, when?
(1) Yes (a) 2013
(b) 2012
(c) 2011
(d) 2010
(e) 2009
(f) 2008)
(2) No

7. Have you ever experienced a surgery before due to IBD?
(1) Yes (a) one time (b) two times (c) three times (d) four times (e) 5 or more times)
(2) No

8. Do you have any other systemic associated disease besides IBD?
(1) Yes, I have. (a) rheumatoid arthritis (b) ankylosing spondylitis (c) psoriasis)
(2) No, I don't have.

9. Have you ever experience cramps or abdominal pain? How many days you usually experience per one week?
(1) Yes, I have (a) one day (b) two days (c) three days (d) four days (e) five days (f) six days (g) everyday)
(2) No, I haven't 
10. Have you had a sudden diarrhea that cannot be tolerated within recent 6 months? How many days you usually experience it?

(1) Yes, I have (a) one day (b) two days (c) three days (d) four days (e) five days (f) six days (g) every day)

(2) No, I don't have

11. How about your status when there are bad symptoms or no symptoms?

\begin{tabular}{|c|c|c|c|c|c|c|}
\hline & & Very often & Often & Sometimes & Rarely & Never \\
\hline $11-2$ & Felt tired, weak and worn out in daily life during remission & 5 & 4 & 3 & 2 & 1 \\
\hline
\end{tabular}

\section{Treatments}

12. Are you meeting health care professionals currently because of IBD? Please choose those you are meeting.

(1) Yes (1) Primary hospitals/ clinics doctor (a) internal medicine (b) family physician (c) surgery department (d) proctological surgery center (e) neuropsychiatry department (f) pediatric department)

(2) General hospital specialist (a) gastroenterologist (b) anorectal surgeon (c) rheumatologist (d) psychiatrist)

(3) Public health center

(4) Oriental medicine clinic

(5) Psychologist

(2) No

13. Have you received steroid medication or are you receiving steroid medication? What do you think about drug effects?

\begin{tabular}{|c|c|c|c|c|c|c|}
\hline & & & Yes & & No & \\
\hline \multirow[t]{2}{*}{$13-2$} & Kept using steroids at the time of severe symptoms & & 1 & & 2 & \\
\hline & & Very often & Often & Sometimes & Rarely & Never \\
\hline $13-3$ & Worried about the effects of long-term effects of steroids on my health & 5 & 4 & 3 & 2 & 1 \\
\hline
\end{tabular}

\section{Impacts of IBD on Daily Life - Impact on Relationship}

14. Do you think that IBD prevents from keeping relationship maintenance / consolidation with acquaintance or relationship formation with new people?

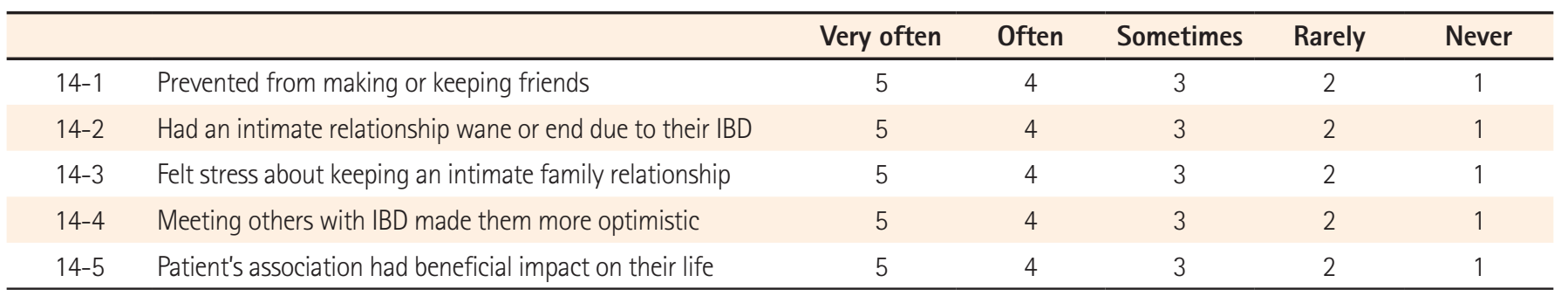


Work Impact

15. Overall work impact of inflammatory bowel disease

\begin{tabular}{|c|c|c|c|c|c|c|}
\hline & & Very often & Often & Sometimes & Rarely & Never \\
\hline $15-1$ & Cancelled or rescheduled an appointment & 5 & 4 & 3 & 2 & 1 \\
\hline $15-2$ & Left school or office early & 5 & 4 & 3 & 2 & 1 \\
\hline $15-3$ & Absence from school or work & 5 & 4 & 3 & 2 & 1 \\
\hline $15-4$ & Took time off from school or work & 5 & 4 & 3 & 2 & 1 \\
\hline $15-5$ & Felt stress about taking time off work or school & 5 & 4 & 3 & 2 & 1 \\
\hline $15-6$ & Received unfair comments at work or school & 5 & 4 & 3 & 2 & 1 \\
\hline $15-7$ & Suffered discrimination or being ostracized & 5 & 4 & 3 & 2 & 1 \\
\hline $15-8$ & Decline in income or academic ability & 5 & 4 & 3 & 2 & 1 \\
\hline $15-9$ & Unable to perform their full potential & 5 & 4 & 3 & 2 & 1 \\
\hline
\end{tabular}

16. What is the number of days which is absent from school or work or left on vacation within recent 6 months?

(Total day(s))

\section{Economic Impact}

17. How much money do you spend per one month for the treatment of IBD?

$\begin{array}{llll}\text { (1) } 50 \text { million won or less } & \text { (2) 50 100 million won } & \text { (3) 100 200 million won } & \text { (4) } 200 \text { million or more }\end{array}$

18. To what extent is IBD likely to affect your finance?

\begin{tabular}{|c|c|c|c|c|c|c|}
\hline & & Very often & Often & Sometimes & Rarely & Never \\
\hline $18-1$ & Stopped medical treatment due to economic burden & 5 & 4 & 3 & 2 & 1 \\
\hline $18-2$ & Felt sorry for my family bearing treatment cost & 5 & 4 & 3 & 2 & 1 \\
\hline $18-3$ & The quality of life had decreased due to economic burden. & 5 & 4 & 3 & 2 & 1 \\
\hline $18-4$ & Having felt like committing suicide & 5 & 4 & 3 & 2 & 1 \\
\hline $18-5$ & Having felt anxiety about the future & 5 & 4 & 3 & 2 & 1 \\
\hline
\end{tabular}

\section{Pregnancy}

19. To what extent is IBD likely to affect your pregnancy, childbirth, and parenting?

\begin{tabular}{|c|c|c|c|c|c|c|}
\hline \multicolumn{2}{|c|}{ *Please indicate your experience or thoughts about pregnancy and childbirth. } & \multirow{2}{*}{$\frac{\text { Very often }}{5}$} & \multirow{2}{*}{$\frac{\text { Often }}{4}$} & \multirow{2}{*}{$\frac{\text { Sometimes }}{3}$} & \multirow{2}{*}{$\frac{\text { Rarely }}{2}$} & \multirow{2}{*}{$\frac{\text { Never }}{1}$} \\
\hline $19-1$ & Did not want marry (because of having guilty of spouse) & & & & & \\
\hline $19-2$ & Did not want to get pregnant & 5 & 4 & 3 & 2 & 1 \\
\hline $19-3$ & $\begin{array}{l}\text { Did not want to get pregnant with a fear of harming babies. } \\
\text { (Miscarriage, fetal deformities, and premature birth, etc.) }\end{array}$ & 5 & 4 & 3 & 2 & 1 \\
\hline $19-4$ & $\begin{array}{l}\text { Did not want to get pregnant with a fear that my disease might be } \\
\text { aggravated }\end{array}$ & 5 & 4 & 3 & 2 & 1 \\
\hline $19-5$ & I am afraid that my disease is passed down to my children. & 5 & 4 & 3 & 2 & 1 \\
\hline $19-6$ & Stopped medication for breastfeeding (I think I should stop it.) & 5 & 4 & 3 & 2 & 1 \\
\hline $19-7$ & My child is healthy. & 5 & 4 & 3 & 2 & 1 \\
\hline $19-8$ & $\begin{array}{l}\text { Had to stop all drugs during pregnancy (I think taking therapeutic } \\
\text { medicines should be stopped during pregnancy.) }\end{array}$ & 5 & 4 & 3 & 2 & 1 \\
\hline $19-9$ & Stopped breast feeding (I thought that I should stop it) & 5 & 4 & 3 & 2 & 1 \\
\hline
\end{tabular}




\section{Expectation / Requirement for Disease Diagnosis / Treatment Environment}

20. Which is the most expectation from IBD treatment / management? Please pick up the most three important things in the ranking order.

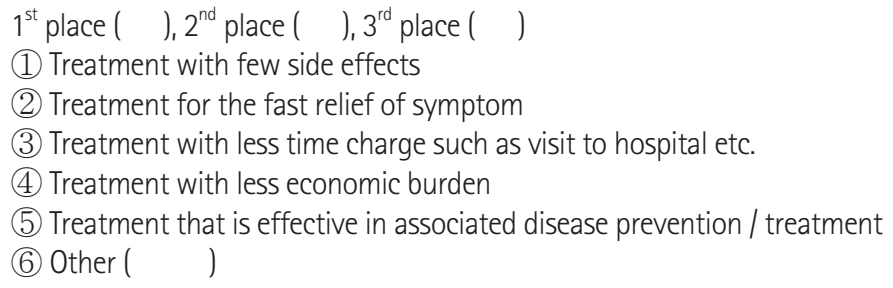

21. What do you think about the treatment / management environment improvement / development of the inflammatory bowel disease (IBD)?

\begin{tabular}{|c|c|c|c|c|c|c|}
\hline & & $\begin{array}{l}\text { Strongly } \\
\text { agree }\end{array}$ & Agree & Neutral & Disagree & $\begin{array}{l}\text { Strongly } \\
\text { disagree }\end{array}$ \\
\hline $21-1$ & $\begin{array}{l}\text { Hope that the government support for IBD treatment expenses will be } \\
\text { expanded }\end{array}$ & 5 & 4 & 3 & 2 & 1 \\
\hline $21-2$ & $\begin{array}{l}\text { Hope that the government support for IBD diagnosis expenses will be } \\
\text { expanded }\end{array}$ & 5 & 4 & 3 & 2 & 1 \\
\hline $21-3$ & $\begin{array}{l}\text { Hope that the government support for IBD-related auxiliary treatment } \\
\text { (such as probiotics etc.) will be expanded }\end{array}$ & 5 & 4 & 3 & 2 & 1 \\
\hline $21-4$ & $\begin{array}{l}\text { Hope that efforts will be made to alleviate prejudice and misconceptions } \\
\text { against IBD patients and increase related awareness }\end{array}$ & 5 & 4 & 3 & 2 & 1 \\
\hline
\end{tabular}

\section{Disease-related Information Acquisition}

22. Please tell us how to get information about inflammatory bowel disease (IBD) in the ranking order.

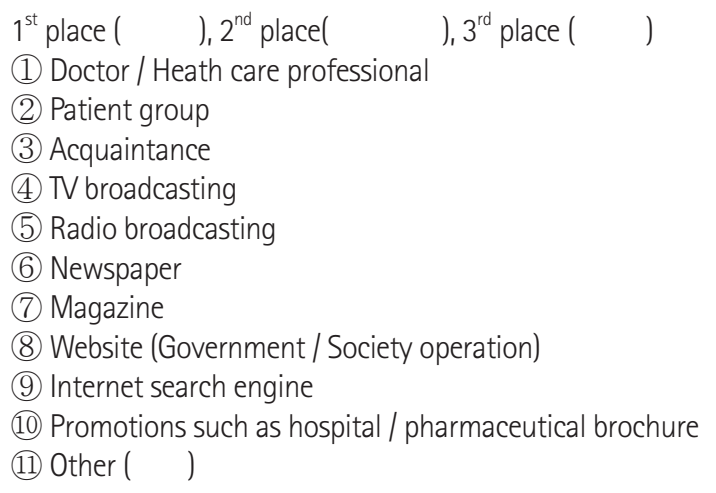

23. Tell us what you want to know inflammatory bowel disease (IBD) specifically. 